This item was submitted to Loughborough's Research Repository by the author.

Items in Figshare are protected by copyright, with all rights reserved, unless otherwise indicated.

\title{
Developments in construction-scale additive manufacturing processes
}

PLEASE CITE THE PUBLISHED VERSION

http://dx.doi.org/10.1016/j.autcon.2011.06.010

\section{PUBLISHER}

(C) Elsevier B.V.

\section{VERSION}

AM (Accepted Manuscript)

\section{LICENCE}

CC BY-NC-ND 4.0

\section{REPOSITORY RECORD}

Lim, Sungwoo, Richard A. Buswell, Thanh T. Le, Simon A. Austin, Alistair G.F. Gibb, and Tony Thorpe. 2019. "Developments in Construction-scale Additive Manufacturing Processes". figshare.

https://hdl.handle.net/2134/9176. 
This item was submitted to Loughborough's Institutional Repository (https://dspace.lboro.ac.uk/) by the author and is made available under the following Creative Commons Licence conditions.

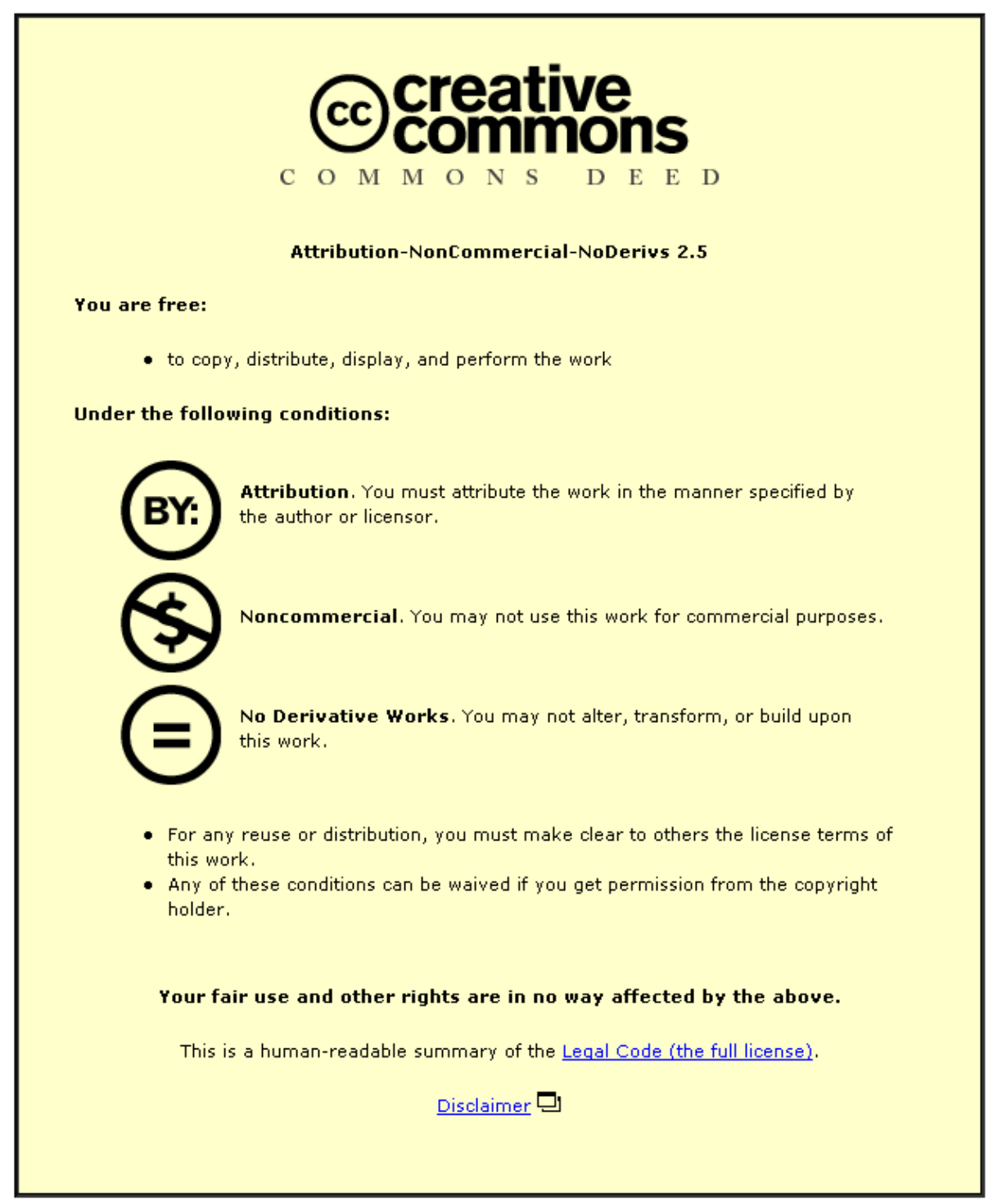

For the full text of this licence, please go to: http://creativecommons.org/licenses/by-nc-nd/2.5/ 


\title{
Developments in construction-scale additive manufacturing processes
}

\author{
S. Lim*, R. A. Buswell, T. T. Le, S. A. Austin, A. G. F. Gibb, and T. Thorpe \\ * Corresponding author: s.lim@lboro.ac.uk
}

\begin{abstract}
Additive manufacturing in construction is beginning to move from an architect's modelling tool to delivering full-scale architectural components and elements of buildings such as walls and facades. This paper discusses large-scale additive manufacturing processes that have been applied in the construction and architecture arena and focuses on 'Concrete Printing', an automated extrusion based process. The wet properties of the material are critical to the success of manufacture and a number of new criteria have been developed to classify these process specific parameters. These criteria are introduced and key challenges that face construction scale additive manufacturing are presented.
\end{abstract}

Keywords - concrete printing, construction automation, digital fabrication, freeform construction, additive manufacturing

\section{Introduction}

A number of drivers are pushing construction towards automation: A reduction in labour for safety reasons; reducing construction time on site; production costs; and/or to increase architectural freedom. There are numerous examples of automation such as, automated bricklaying [1], sprayed concrete [2], precast techniques [3] as well as robotic milling to create moulds for construction panels and shaping panels for facades based on techniques used in shipbuilding [4]. The development of Building Information Modelling will undoubtedly increase the use digital information and is likely drive the application of automated modelling and manufacturing process within construction.

Additive manufacturing (AM) is defined by American Society for Testing and Materials as 'the process of joining materials to make objects from 3D model data, usually layer upon layer' [5]. Over the last 30 years, improvements in materials and process, coupled with clever design has resulted in successful commercial realisation [6, 7]. In addition, the linear cost/production relationship for small batch production in Figure $\mathbf{1}$ is unique in the manufacturing sector and provides a strong business case for mass customisation, or personalisation of components. A comparison is made between AM and injection moulding demonstrates that it can be cost effective for smaller batches (up to 10,000).

AM has become an integral part of modern product development [8] and the technology has been commercialised to the extent where machines are now affordable for home use [9-11]. Industrial applications are apparent in aerospace and automotive manufacturing, a wide range of medical applications [12] and for the production of prototyping models for aesthetic and functional testing [13]. Additive techniques are normally used to make small components, on the 'desktop' scale, although specialist companies such as Materialise [6] have SLA machines with dimensions up to $2100 \times 600 \times 780 \mathrm{~mm}$ that can build entire car bumpers in one machine. 


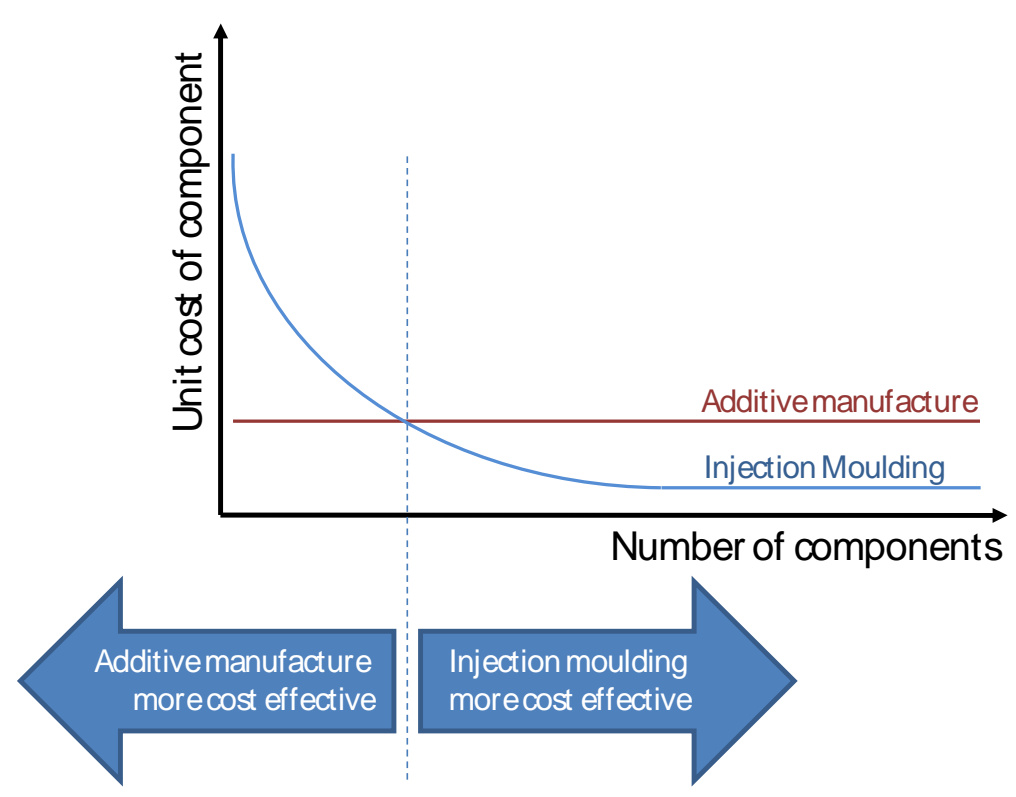

Figure 1: Diagram of cost case for additive manufacturing (reproduced from [8]).

In construction virtually every wall, floor, panel, partition, structure and facade is unique in dimension, which means either standard sized materials are cut down to fit, or bespoke moulds are created to form each component. In the latter case economies of scale drive the need to design multiple copies of identical elements on a project. There is a clear cost-based opportunity to save time and materials by reducing waste and the need for formwork/mould making. There is also significant potential to reduce the quantity of materials used through optimisation of form and the implementation of additional 'engineering function' within components. The computational design environment promises the freedom to design around individuals and the environment. Furthermore, AM may remove the need for replication of components, giving designers freedom to make each part unique.

This paper describes three construction scale AM processes capable of manufacturing large components. The similarities and differences are highlighted and the importance/necessity of developing these methods for specific applications discussed. The paper then focuses on one process (Concrete Printing) to identify the issues associated with manufacturing parts for construction applications using these large-scale techniques.

\section{Large scale additive manufacturing in construction and architecture}

The first attempt at using cement based materials in an approach to AM was suggested by Pegna [14]. Currently there are three large-scale AM processes targeted at construction and architecture in the public domain, namely: Contour Crafting [15], D-Shape (Monolite) [16] and Concrete Printing [17]. All three have proven the successful manufacture of components of significant size and are suitable for construction and/or architectural applications (Figure 2).

The deposition head mounting is, either frame, robot or crane mounted. Contour Crafting has been developed to be a crane-mounted device for on-site, in-situ applications. Both DShape and Concrete Printing are gantry based off-site manufacturing processes, although there is no specific reason why either process cannot be used on-site.

The three processes are all similar in that they build additively, however the processes have been developed for different applications and materials, which results in each having distinct 
advantages. The D-Shape process uses a powder deposition process, which is selectively hardened using a binder in much the same way as the Z-Corp 3D printing process [18]. Each layer of build material is laid to the desired thickness, compacted and then the nozzles mounted on a gantry frame deposit the binder where the part is to be solid. Once a part is complete it is then dug out of the loose powder bed. The process has been used to create $1.6 \mathrm{~m}$ high architectural pieces called "Radiolaria" (see the top left picture in Figure 2).

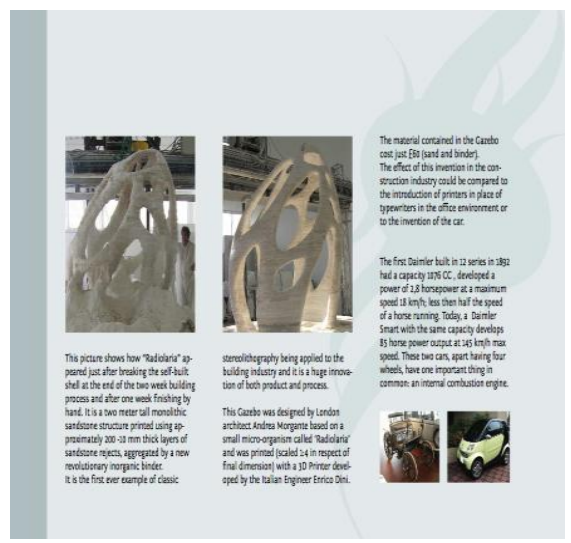

C

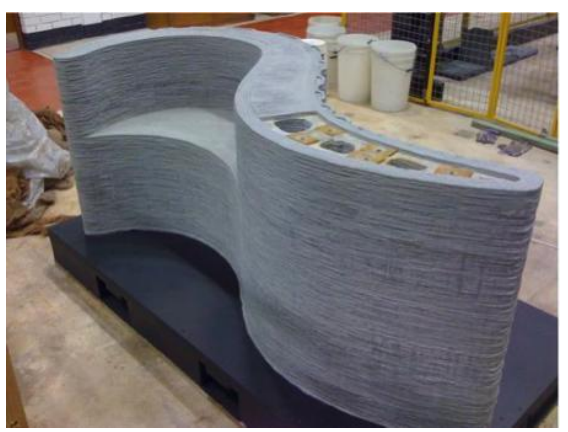

Figure 2: Examples of full scale builds from each process, (a) D-Shape, top left,

(b) Contour Crafting, right and (c) Concrete Printing, bottom left.

Contour Crafting has been in development for some years [15, 19-22], and is based on extruding a cement-based paste against a trowel that allows a smooth surface finish created through the build up Figure 2).

Concrete Printing is also based on the extrusion of cement mortar, however the process has been developed development has been to retain 3-dimentional freedom

Figure 2 demonstrates the finish that is achievable direct from manufacture.

Traditional AM processes are used to create 3-dimensional objects and therefore when the part has an overhanging section, the material requires

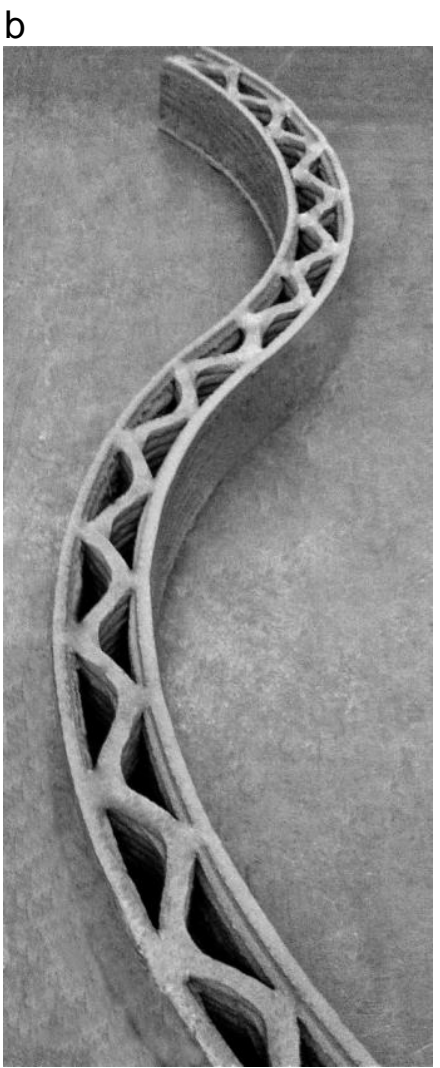

of subsequent layers. It has been developed to address the issue of highspeed automated construction, and the current deposition head is capable of laying down material to create a full width structural wall with the minimum use of material (top-right hand picture in

and has a smaller resolution of deposition, which allows for greater control of internal and external geometry. The component pictured in the bottom of

support for its self-weight. This is usually achieved one of three ways: the build material is used to create a very fine structure similar to scaffolding that is broken away after the build is complete; a second material is deposited that is easy to remove; or, in powder based systems, 
the unconsolidated material actually provides support. Contour Crafting currently produces vertical elements largely in compression; when a doorway or window is required a lintel is placed to bridge the gap and the wall can be placed above. It thus avoids the cantilever problem. Both Concrete Printing and DShape require additional support to create overhangs and other freeform features: DShape is a powder based process and uses the unconsolidated material for support; Concrete Printing uses a second material, in a similar manner to the Fused Deposition Modelling Process. The disadvantage of these types of process is an additional deposition device is requiring more maintenance, cleaning and control instructions and the secondary structure must be cleaned away in a post processing operation. The simplicity of powder-based approaches such as DShape must be balanced against the large volumes of material that have to be deposited in the build area and then removed to reveal the part. These similarities and differences are summarised in Figure 3.

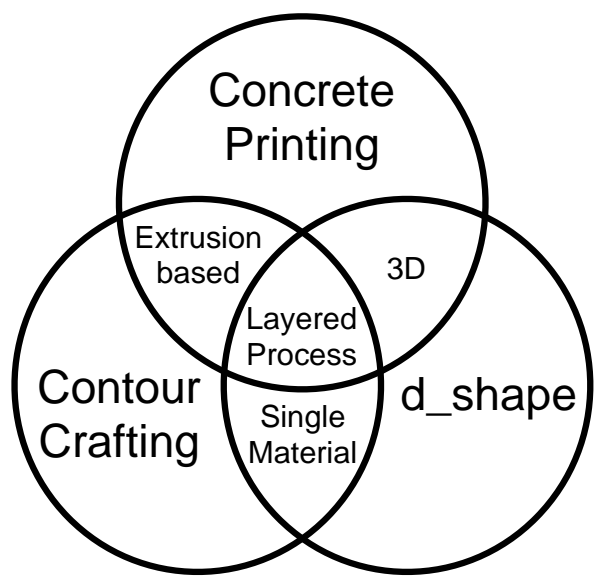

Figure 3: Similarities between the processes.

The print resolution (in terms of layer depth) varies from $4 \sim 6 \mathrm{~mm}$ in Concrete Printing and D-Shape to $\sim 13 \mathrm{~mm}$ [21] in contour crafting. The principle trade off in layer depth in all three processes is against build speed, i.e. number of layers required to build the desired height. Secondary influencing factors are the minimum feature size (i.e. the smallest detail that can be built), surface finish and material characteristics. The extrusion processes are heavily influenced by mix design, particle size limiting the fineness of extrusion and the stability of the extruded filament creating an upper bound. In the D-Shape process, issues such as the penetration of the binder through each layer and the degree of 'bleeding' that occurs around the point of injection will be important parameters.

Print speed is also affected by the build material and/or binder deposition rate. Contour Crafting avoids lengthy cycle times between layers by printing an entire layer with two passes of the deposition head. The process uses a large diameter extrusion resulting in a high layer build-up rate, minimising the printing time. D-Shape uses a gantry with multiple nozzles mounted in series that requires a single traverse per layer, although the build material must be pushed over the entire build area, compressed and flattened. Concrete Printing utilises a single deposition nozzle, which unlike D-Shape, means that only the required material volume is deposited for the build; however, the single nozzle approach inevitably limits the deposition rate because the nozzle must traverse the entire build area. Increasing the cross-sectional area of the extrusion correlates directly on the deposition rate, as does the number of nozzles simultaneously depositing.

Materials in all three techniques harden through a curing process, which is inherently less controllable that the heat or UV based phase change methods of conventional additive methods. Contour Crafting and Concrete Printing are wet processes while D-Shape is predominantly a 'dry' process. Hardened properties of the three techniques are described in Table 1.

Finishing and post processing differ. Concrete Printing produces a characteristic ribbed finish, which can be controlled and designed to exploit the effect. Smooth surfaces, however, require either; the trowelling of wet material during the build process; grinding back the printed finish to a smooth surface post build; or the addition of conventional 
finishes such as plaster or concrete render onto the printed finish. The design of the Contour Crafting deposition head allows smoothing to be carried out during the build phase. Similar to Concrete Printing, the D-Shape process produced a texture of finish, which requires grinding and polishing if such a surface is desired.

Table 1: Existing research and practice related to AM processes in Construction

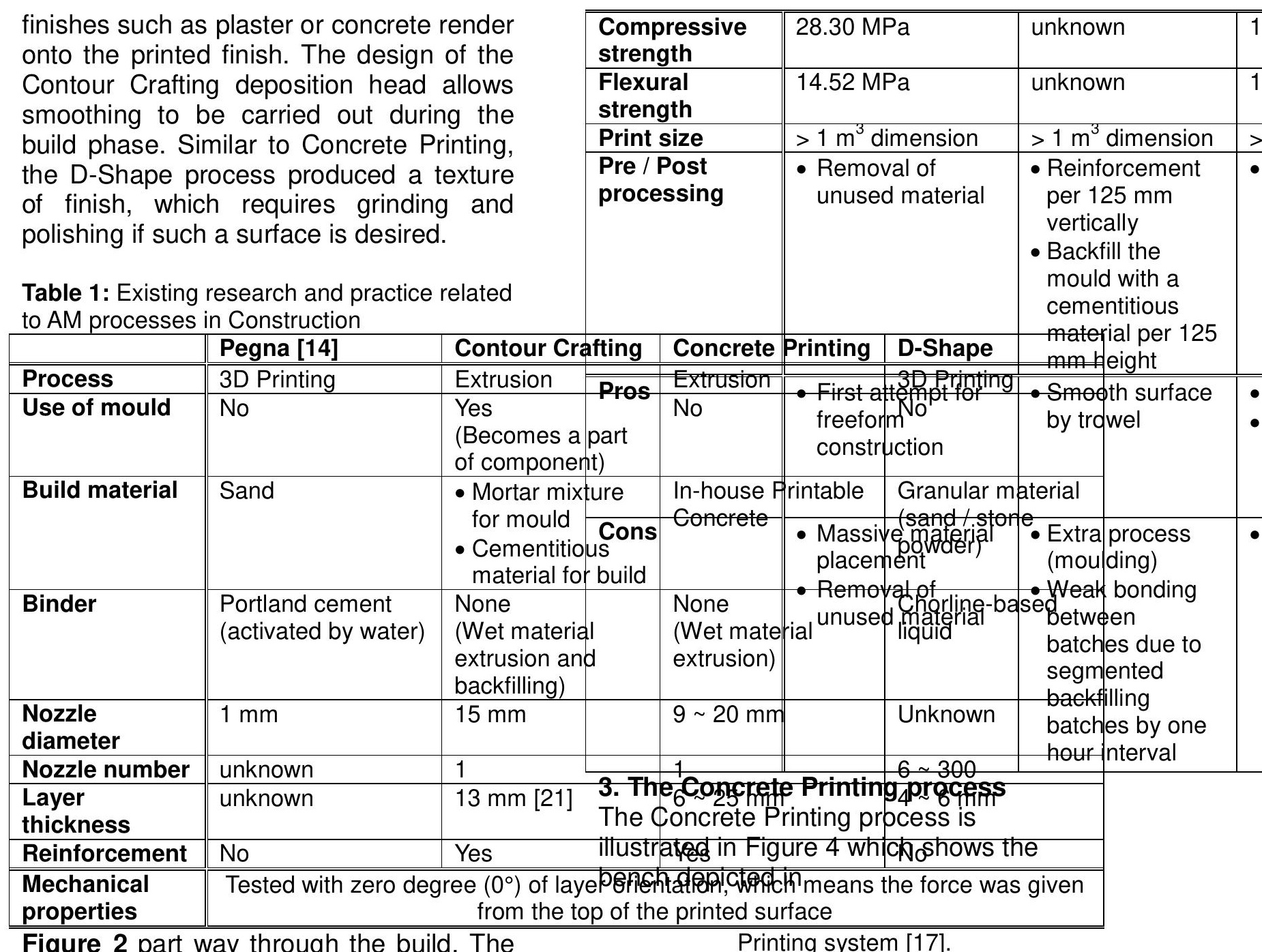

Figure 2 part way through the build. The interlayer reinforcement mesh was installed to support the overhanging bench seat, and was covered over by subsequent layers.

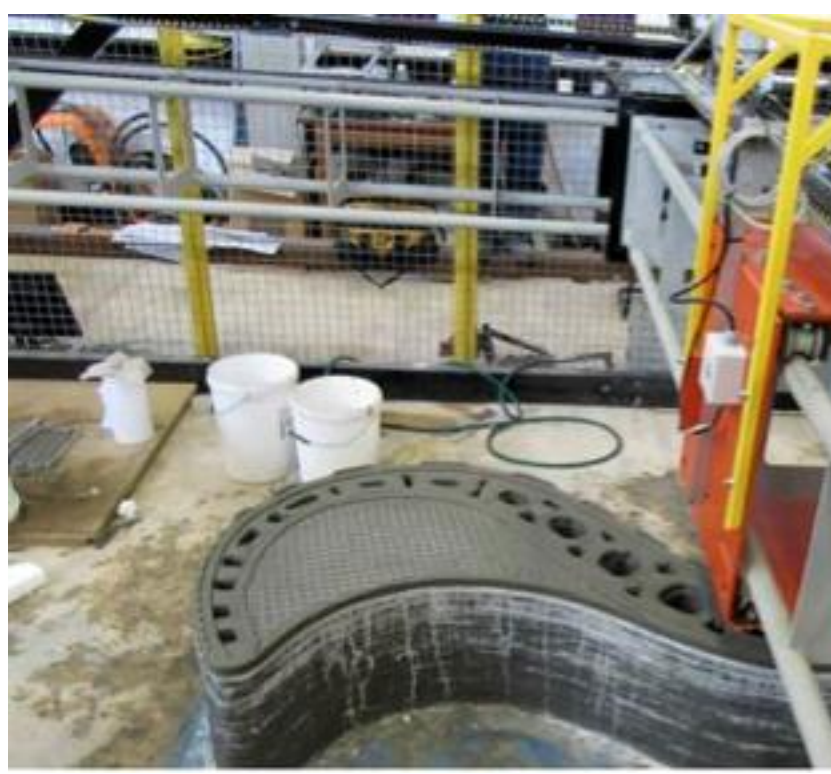

Figure 4: 3D printing frame of Concrete
The manufacturing process is similar to conventional additive processes including the component design in solid geometry, the conversion of this solid geometry to machine instructiofs, the printing of the component and finally post processing which indudes he removal of support structure and any surface finishing that is recuived 3.1 Dáta preparat

Ext usion waks particularly well when it is dene continuously but problems such as over-printing (too much material deposited) arise when the material flow is interrupte and under-printing (a pause in deposition that doesn't coincide with nozzle movement) when re-starting. These difficulties can be addressed through the better design of applicators, tuning the machine operating parameters or modifying the tool path. 
The latter optimises the printing path to minimise print time and on/off operations. The reduction in build time is dependent on build complexity; higher complexity with more stop/starts has more scope to minimise print-time. The approach restructures the initial printing path by linking the start of one path to the path that finishes at the same location. The problem is created because standard software tools generate G-code (the common name for general CNC programming language) for each layer of the build and have not been optimised for printing and non-printing traverse. Simulations of G-code generated by a commercial CNC software and in-house developed optimisation script has demonstrated that it is possible to save up to $30 \%$ on build time between the nonoptimised and optimised printing path, which is significant. Figure $\mathbf{5}$ demonstrates the differences in the tool paths (white line) generated.

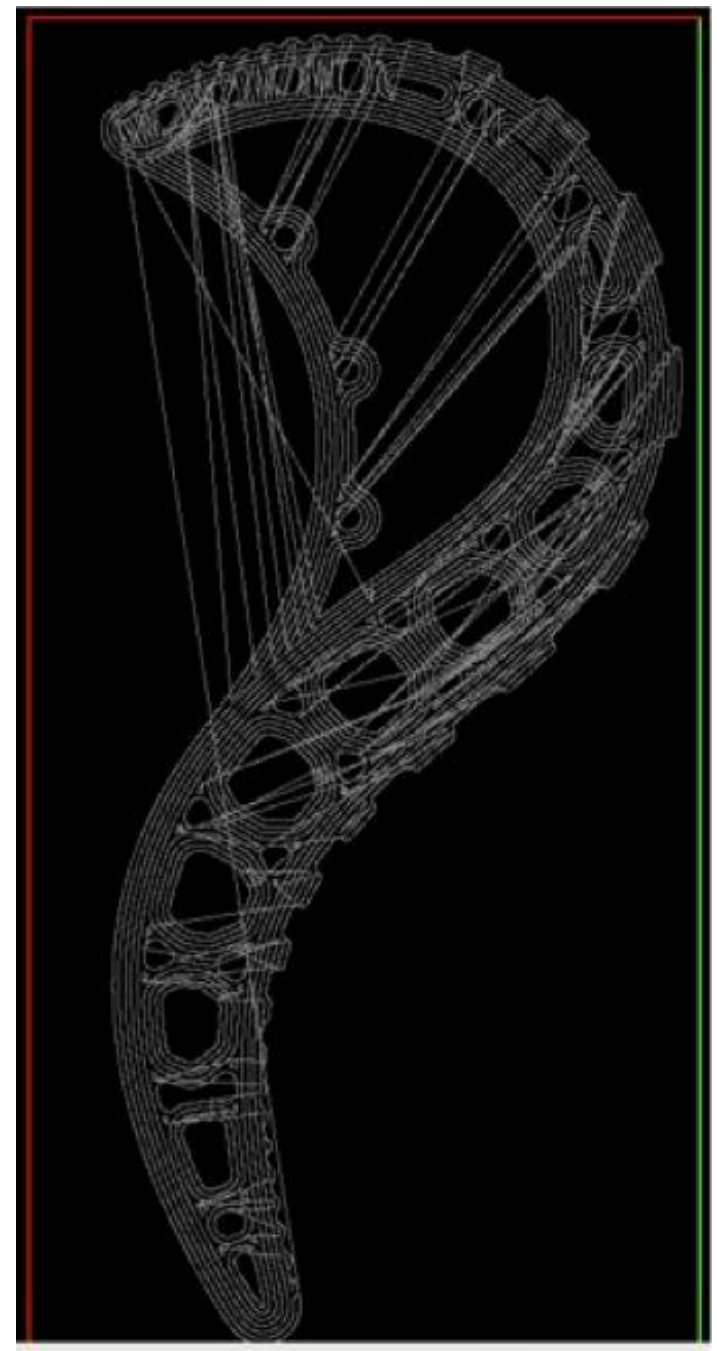




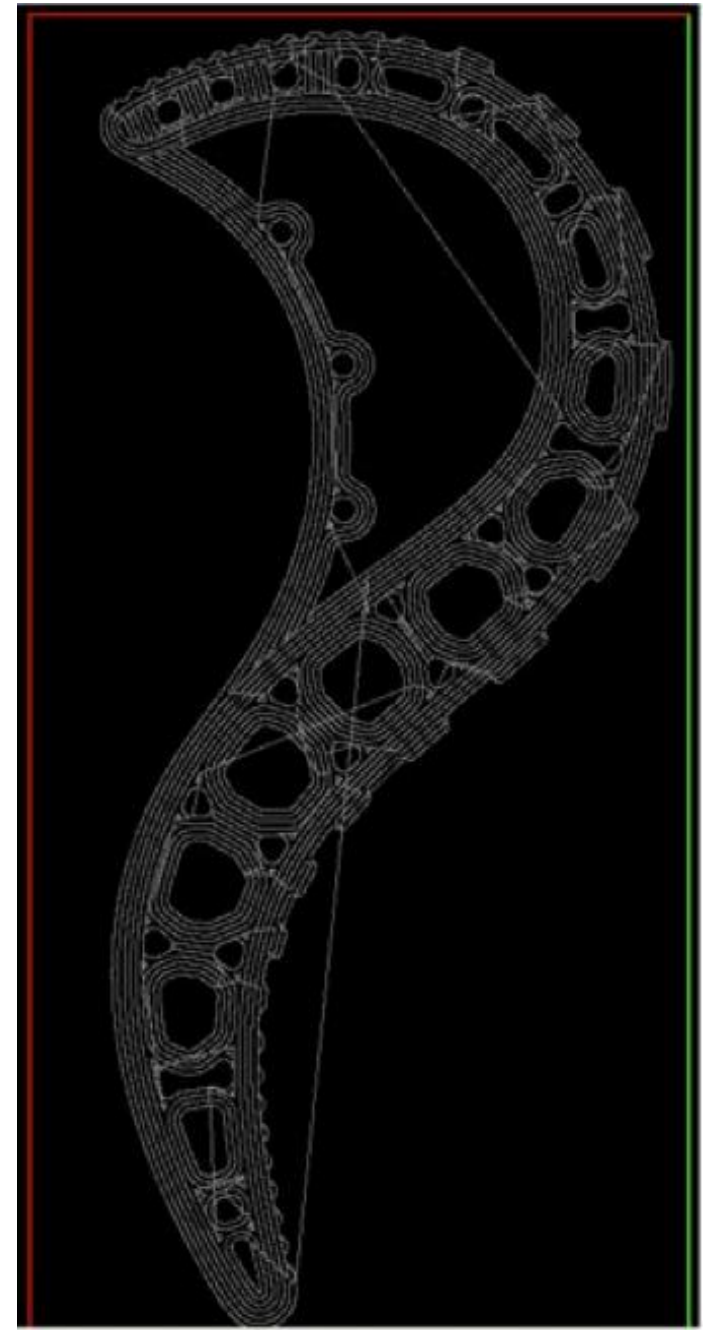

(a) Non-optimised printing path

(b) Optimised

printing path

Figure 5: Comparison of printing time between non- optimised and

optimised printing paths using a CNCSimulator.

\subsection{Materials}

A high-performance cement-based mortar has been developed for Concrete Printing which comprises $54 \%$ sand, $36 \%$ reactive cementitious compounds and $10 \%$ water by mass. What is important for the application of mortars in additive processes is the wet properties in terms of pumpability and the stability of the extrusion. Four key characteristics of wetprocess AM can be identified:

(i) Pumpability - The ease and reliability with which material is moved through

Figure 2). The resultant vertical surface resolution using the extrusion-based approach is heavily depending on layer thickness. Figure 6 depicts parts created the delivery system;

(ii) Printability - The ease and reliability of depositing material through a deposition device;

(iii) Buildability - The resistance of deposited wet material to deformation under load; and

(iv) Open time - The period where the above properties are consistent within acceptable tolerances.

A detailed assessment of these properties is given elsewhere [23], however these properties will all vary depending on the mix design, the delivery system and the deposition device. The material hardened properties may also be affected by the process. The compressive strengths of extruded, deposited material are between $80 \%$ and $100 \%$ of the cast equivalent. The flexural strength of printed in-situ specimens is not significantly different from that of standard cast specimens although it is dependent on the orientation of the printing; the parts are weaker when the load axis is perpendicular to the printed surface while parallel to the filament.

In terms of the material cost, the mix formulation is comparable with other high cement content mixes. The advantage of the concrete printing process, however, is that the 3D model can be optimised for strength prior to manufacture and hence the final print need only use the minimum amount of material, which is not feasible with conventional methods of construction manufacture.

\subsection{Design and Printing}

In terms of material batching, the filling of the feed hopper with the mixed material takes about 5 minutes and the open time of the material exceeds 1 hour, and hence there is no noticeable discontinuity in the built structure. One of the by-products of the process is the ribbed surface finish (

in gypsum using $22 \mathrm{~mm}$ by $15 \mathrm{~mm}(\mathrm{H})$ and $9 \mathrm{~mm}$ by $6 \mathrm{~mm}(\mathrm{H})$ extrusions. If the finish is not to be polished, the unique texture can inform the design of the component. 
The layers give printed objects a sense of the materiality of the build process, and has inspired the design in Figures Figure 7 and Figure 8.

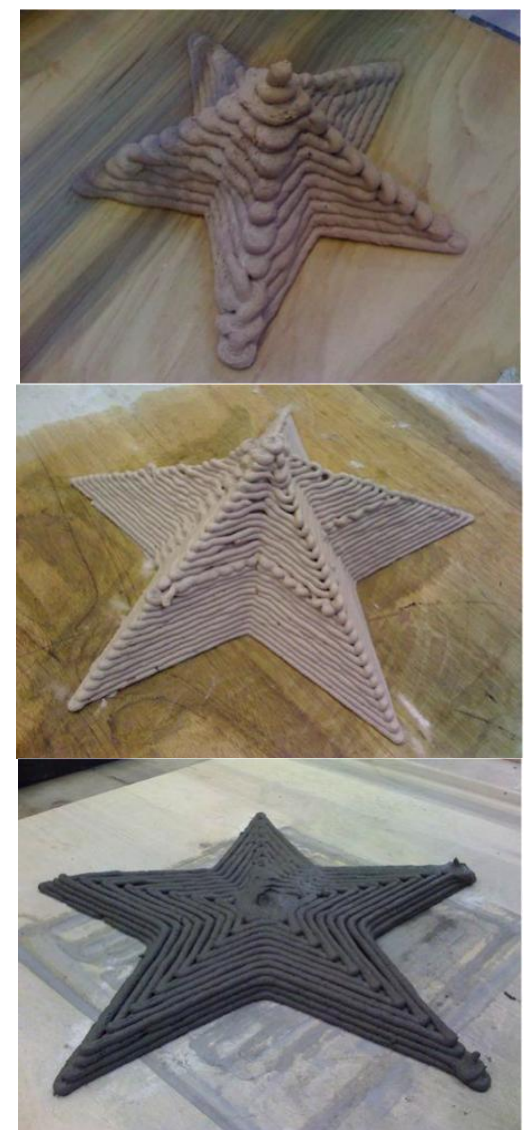

Figure 6: Printing examples of two resolutions. Left: 22 by $15 \mathrm{~mm}$ using gypsum. Middle and Right: 9 by $6 \mathrm{~mm}$ using gypsum and cementbased materials.

The extruded filament has an oval crosssection to maximise the interface between layers. A round nozzle simplifies the control of the machine by making the direction of head motion independent of deposition direction, which is not the case with square extrusions that require an addition axis of nozzle rotation.

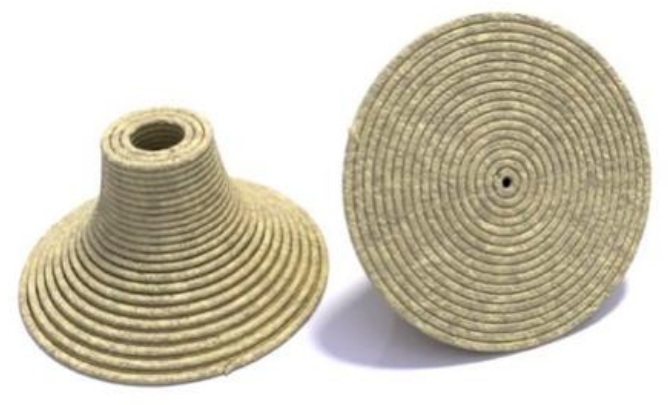

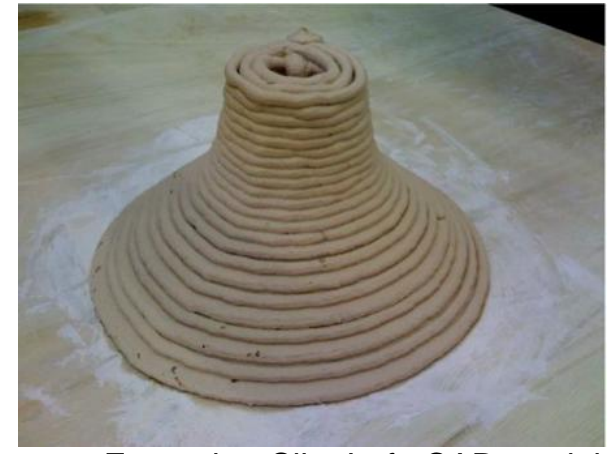

Figure 7: Example - Silo. Left: CAD model and Right: printed with gypsum.

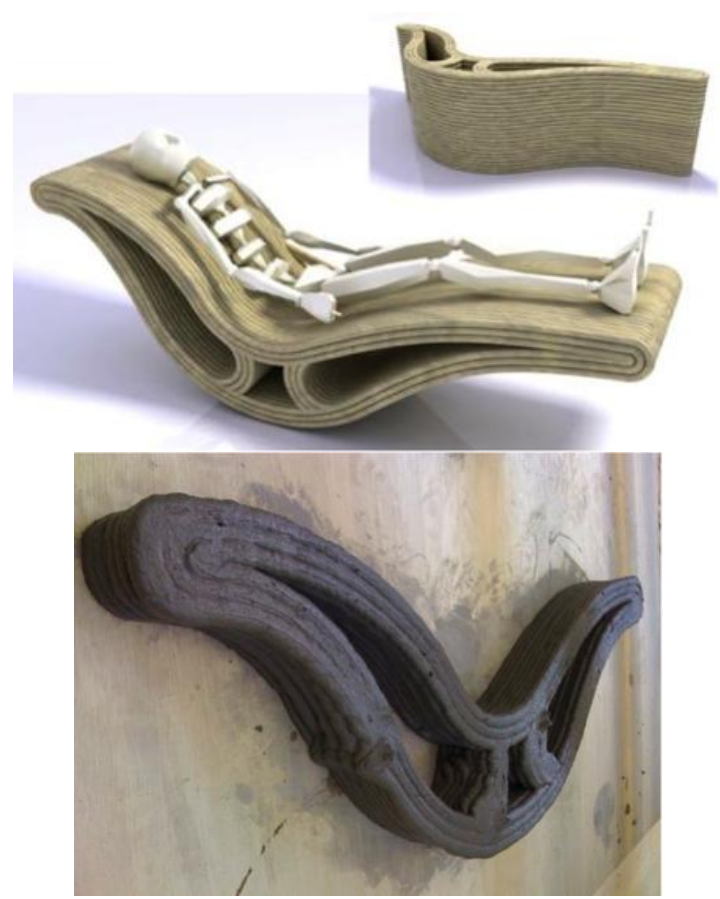

Figure 8: Examples - bed. Left: CAD model and Right: printed with a proprietary mortar product.

Algorithms for random pattern generation were created to explore the correlation between the pump and machine speed as well as flow rate for a particular nozzle diameter. Irregular thickness of filaments, poor bonding and inaccurate filament shapes, particularly with sharp corners in Figure 9, have been minimised by achieving consistent flow rate and appropriate machine speed. 

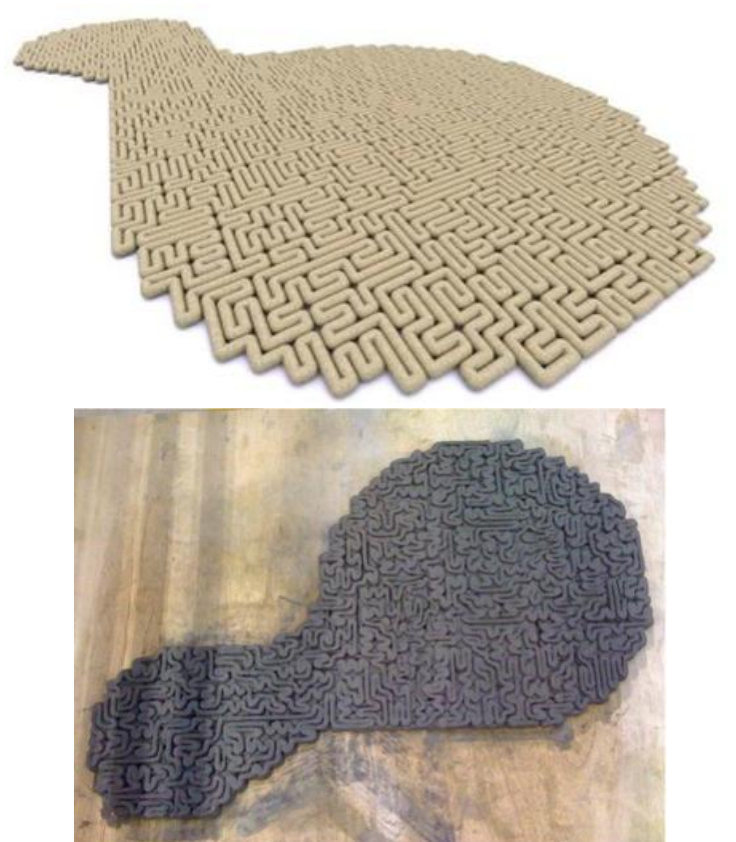

Figure 9: Example - random patterned table.

Left: CAD model and Right: printed model.

Figure 2). The back of the wall has a square wave superimposed onto the surface. The wavelength changes to demonstrate the ability of the process to produce unique components. The front has a smooth surface with an integrated seat. The top layer covers two thirds of the artefact to reveal the internal structure (Figure 10), and the artefact includes 12 voids (white holes in Figure 11) that minimise weight, which could be utilised as acoustic structure, thermal insulation and/or a conduit for building services. The voids consist of various sizes and shapes to follow the curved shape of the artefact.

The component also demonstrates a reinforcement strategy suitable for large components printed using AM. A total of 23 voids (grey holes in Figure 11) were designed to form conduits for the post placement of reinforcement. $8 \mathrm{~mm}$ diameter reinforcing bars were inserted in the voids, post-tensioned and grouted to put the part in to a predetermined compression. This approach offers a simple workable method of incorporating tensile capacity into large cement-based components, demonstrating the potential for automated manufacture of large construction components.

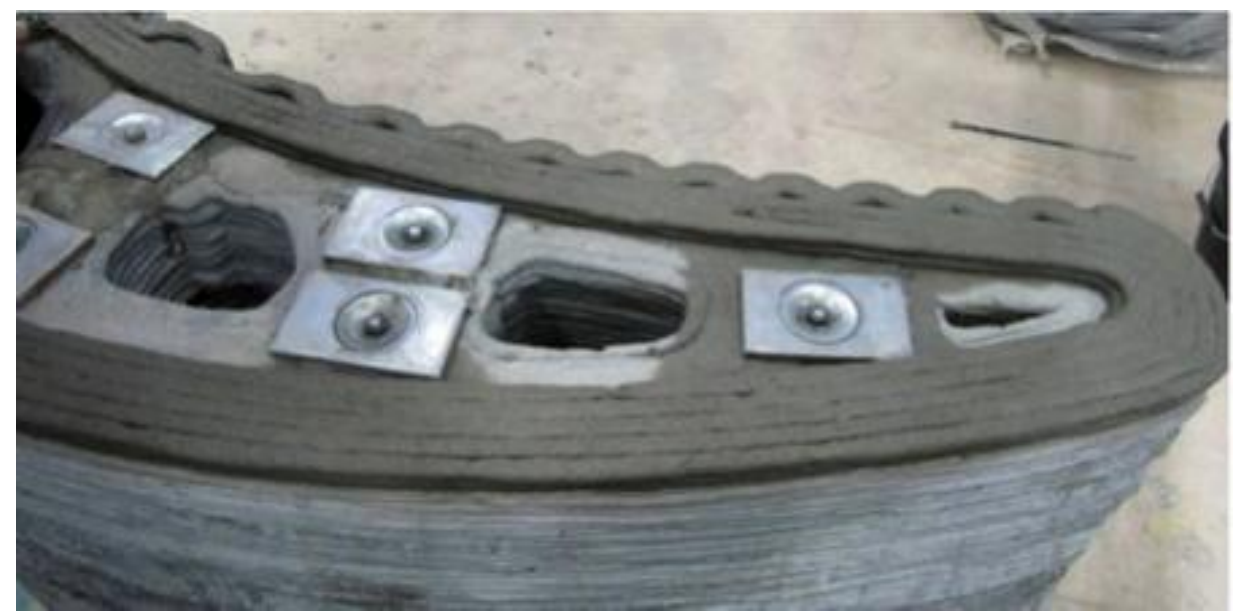

Figure 10: Internal structure including functional voids and reinforcement. 


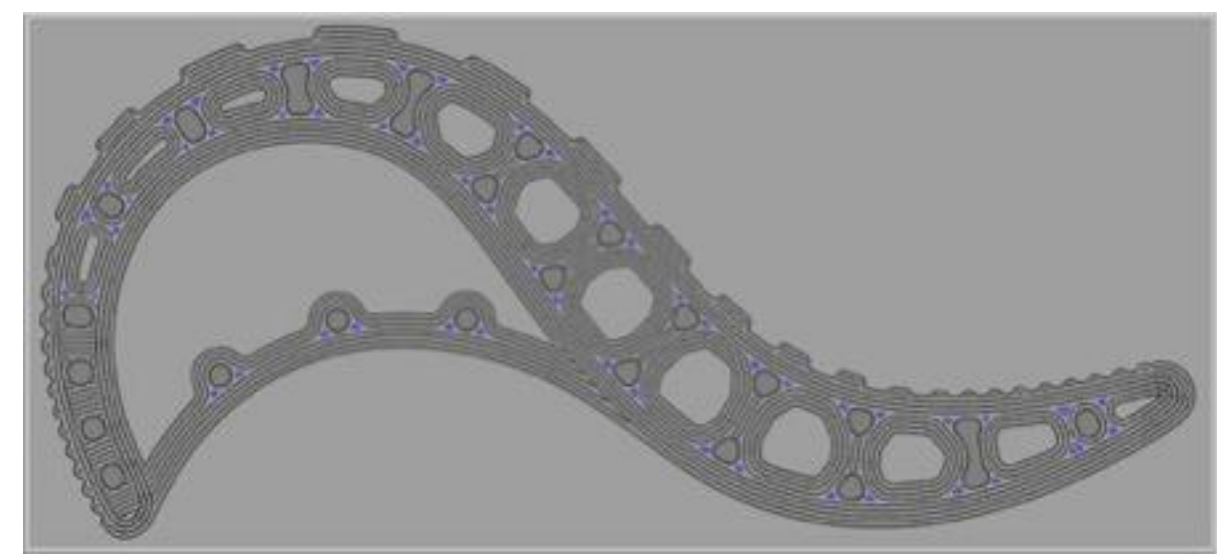

Figure 11: A plan view of the wall-like artefact. The lines indicate the centre line of printed filaments.

\section{Conclusion}

Three large-scale AM processes have been reviewed and compared in terms of their key characteristics. Each has been shown to have strengths and weaknesses, and the exploitation markets have clearly been chosen to align with the specific benefits and minimise the challenges or limitations.

The Concrete Printing process has been explored in detail and evidence presented of freedom of design, precision of manufacture with functional integration, and elimination of labour-intensive moulding, which is not possible with conventional construction processes.

Construction components of any significant size are heavy, up to 5 tonnes being typical. Lifting and moving these parts is non-trivial. This suggests an in-situ deposition approach, printing parts on site followed by assembly or ultimately printing large parts of a building or other infrastructure in-situ (as suggested for Contour Crafting [15]). A disadvantage, however, is the sensitivity of the materials and processes to ambient conditions, which can hamper onsite applications. Alternatively components can be fabricated off-site and transported to construction sites, as well as inevitable safety concerns for operatives. A factory-based approach to the manufacture of large components in a controlled environment is therefore attractive and well aligned with movement within the construction industry away from onsite production to increase quality, speed of production and health and safety.

Additive manufacture of full-scale construction components is still an emerging technology, but one that is becoming a reality. The three large-scale processes presented have different characteristics and have been developed for different applications. Concrete printing has potential in several areas, three markets and example product types being shown in Figure 12. Process refinements will be required to tailor the specific requirements of a manufacturing technique to a specific application, but proof of concept has been demonstrated. As media interest grows in small-scale AM, research into large-scale systems is beginning to reveal the potential for applications in construction. 


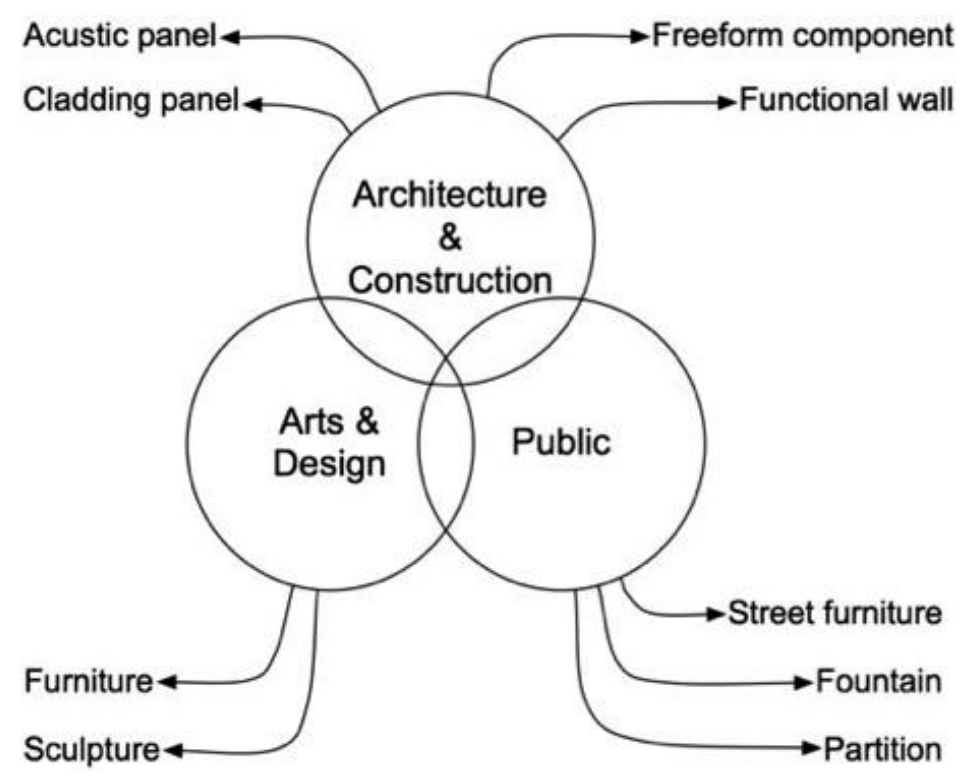

Figure 12: Practical applications of Concrete Printing process.

\section{Acknowledgements}

The work in this paper is funded by Engineering and Physical Sciences Research Council (EPSRC) Grant (EP/E002323/1) through the Innovative Manufacturing and Construction Research Centre at Loughborough University. The authors gratefully acknowledge the technical contributions of John Webster in the development of the CP rig, the help of Jonathan Hales in the laboratory and the assistance of Foster + Partners and Buro Happold in designing the bench.

\section{References}

1. T. Bonwetsch, F. Gramazio, and M. Kohler. "Digitally Fabricating Non-Standardised Brick Walls." Paper presented at the ManuBuild conference proceedings, Rotterdam, 2007.

2. Shotcrete, http://www.shotcrete.co.uk.

3. Buildoffsite, http://buildoffsite.org.

4. Formtexx, http://www.formtexx.com.

5. $\quad$ ASTM. "Astm F2792-10 Standard Terminology for Additive Manufacturing Technologies." American Society for Testing and Materials (ASTM), http://www.astm.org/DATABASE.CART/HISTORICAL/F2792-10.htm.

6. Materialise. "Automotive Testimony: Perfect Bumper Match.", http://www1.materialise.com/materialise/view/en/359256-

Plastic+Omnium+bumper.html.

7. $\quad$ Stratasys. "Urbee, 3d Printed Car Exterier.", http://www.stratasys.com/Resources/Case-Studies/Automotive-FDM-TechnologyCase-Studies/Urbee.aspx.

8. R. Hague, I. Campbell, and P. Dickens. "Implications on Design of Rapid Manufacturing." Proceedings of the Institution of Mechanical Engineers, Part C: Journal of Mechanical Engineering Science, Vol 217, no. 1 (2003), 25-30.

9. $\quad$ PP3DP. "Personal Portable 3d Printer.", http://pp3dp.com.

10. bitsfrombytes. "Affordable 3d Printing.", http://www.bitsfrombytes.com.

11. MakerBot. "Makerbot 3d Desktop Printer.", http://www.makerbot.com.

12. Mark A. Evans, and R. lan Campbell. "A Comparative Evaluation of Industrial Design Models Produced Using Rapid Prototyping and Workshop-Based Fabrication 
Techniques." Rapid Prototyping Journal, Vol 9, no. 5 (2003), 344-51.

13. Shiva Sambu, Yong Chen, and David W. Rosen. "Geometric Tailoring: A Design for Manufacturing Method for Rapid Prototyping and Rapid Tooling." Journal of Mechanical Design, Vol 126, no. 4 (2004), 571-80.

14. J. Pegna. "Exploratory Investigation of Solid Freeform Construction." Automation in Construction, Vol 5, no. 5 (1997), 427-37.

15. B. Khoshnevis, D. Hwang, K. Yao, and Z. Yeh. "Mega-Scale Fabrication by Contour Crafting." International journal of Industrial and System Engineering, Vol 1, no. 3 (2006), 301-20.

16. $\quad$ Enrico Dini. "D_Shape.", http://www.d-shape.com.

17. S. Lim, T. Le, J. Webster, R. Buswell, S. Austin, A. Gibb, and T. Thorpe. "Fabricating Construction Components Using Layer Manufacturing Technology." Paper presented at the Global Innovation in Construction Conference 2009 (GICC'09), Loughborough University, Leicestershire, UK, 13-16 September, 20092009.

18. Z-Corp. "Sls-Based 3d Printers.", http://www.zcorp.com/en/Products/3DPrinters/spage.aspx.

19. Behrokh Khoshnevis, Satish Bukkapatnam, Hongkyu Kwon, and Jason Saito. "Experimental Investigation of Contour Crafting Using Ceramics Materials." Rapid Prototyping Journal, Vol 7, no. 1 (2001), 32-41.

20. B. Khoshnevis. "Automated Construction by Contour Crafting-Related Robotics and Information Technologies." Automation in Construction, Vol 13, no. 1 (2004), 5-19.

21. Dooil Hwang, and Behrokh Khoshnevis. "Concrete Wall Fabrication by Contour Crafting." Paper presented at the 21st International Symposium on Automation and Robotics in Construction (ISARC 2004), Jeju, South Korea, 2004.

22. Zhenghao Yeh, and Behrokh Khoshnevis. "Geometric Conformity Analysis for Automated Fabrication Processes Generating Ruled Surfaces: Demonstration for Contour Crafting." Rapid Prototyping Journal, Vol 15, no. 5 (2009), 361-69.

23. T. T. Le, S. A. Austin, S. Lim, R. A. Buswell, A. G. F. Gibb, and A. Thorpe. "Mix Design and Fresh Properties for High-Performance Pritning Concrete." RILEM Material \& Structure journal, 2011 (submitted in 2011). 